\title{
4 Trusting robots?
}

\section{On the concept of trust and on forms of human vulnerability}

Svenja Wiertz

\section{Abstract}

We live in an aging society where more and more adults are in need of special care. One strategy pursued in this situation is furthering the development of assistive technology devices that could supply some form of care to older adults. This paper aims to show some of the potentials and limitations of replacing human caregivers with assistive technological devices by looking at concepts of trust and reliance. Trust will be introduced as a moral relation that cannot be realized in interaction with robots. Insofar as care relationships have at least the potential of being trust relationships, replacement of caregivers by care robots can only ever be a partial replacement in regard to some specific function. Care relationships, however, will also often be relationships of dependence, which include a high degree of vulnerability. When we depend on another, we often do not have the choice to leave a relationship where we experience broken trust or mistrust. Such relationships are not perceived as valuable and can inflict significant harm. The option to rely on assistive technology systems instead of being dependent on human caregivers can thus prima facie be understood as a valuable option of gaining a degree of independence.

\subsection{Types of care robots and the possibility of replacement}

We live in an aging society where more and more adults are in need of special care. In Germany, the existing infrastructure and the number of people trained as nurses are not sufficient to meet the current demand and the gap is expected to widen in the next few decades (Pfeiffer 2018; Sahmel 2018; Becker 2017).

One strategy the German government is pursuing in this situation is furthering the development of assistive technology devices that could provide some form of care to older adults (Bundesministerium für Bildung und Forschung 2018). Such technological devices have been successfully developed and implemented. The robot seal Paro is showing promising results as a therapeutic tool in working with patients of dementia (Bemelmans et al. 2015). Robot arms have been introduced in hospitals to help nurses with physically challenging tasks like lifting and shifting of patients. The term "care robot" is used here in a very broad sense. The robot arms are not meant to directly assist people in need of care but to assist the human caregivers in performing their tasks. Other care robots are mainly used for bridging physical distances - like telepresence robots, which are designed to enable communication and to a certain degree interaction between two persons without a need for physical presence. Even 
robots developed for tasks like cleaning and transportation are sometimes discussed under the label "care robots" when they are designed to be used in hospitals or nursing homes (Graf and Klein 2018). All these technologies can raise interesting ethical questions, but they will not be considered here.

Only a limited number of assistive technology devices are meant to interact with people directly and autonomously, where "autonomously" refers to the limited sense in which technological devices can function without being directly controlled by a person - a very limited sense of the word that should not be mixed up with the concept of autonomy of persons (Beer et al. 2014; Gräb-Schmidt and Stritzelberger 2018). The Care-o-bot developed by the Fraunhofer-Institut is one example for this kind of care robot. Other devices do not only interact with people in need of special care and they need not be robots. Something like "Alexa” installed on an Amazon Echo system would fall into this category as well. Both have in common that people are meant to interact with them directly, on a regular basis, without any human intermediary. In these cases it is conceivable that the interaction with the device negates the need for human interaction.

In this paper I want to contrast some of the possibilities and limitations of human caregiving on the one hand and assistive technology on the other. To do this, I will introduce a concept of interpersonal trust as a moral concept and differentiate it from the concept of reliance regarding technological devices. I will briefly outline both concepts in their positive form before turning to forms of disappointed trust and misplaced reliance - shedding some light on what can happen when trust relationships go wrong. This analysis will be put in context with a conception of human vulnerability, to show how we as humans are generally vulnerable and how we are specifically vulnerable in trust relationships. We cannot, I will argue, trust in assistive technology devices in the same way we trust in humans. This means that we also cannot be hurt in the same ways. The aim of this paper is thus to identify some potential of the development of assistive technology in spite of its obvious limitations.

\subsection{Trust}

Annette Baier (1996) has defended a view on trust that is not new but still rather influential today. While it has been challenged in numerous ways, it captures appropriately at least some central intuitions on trust. And it is simple enough to mark some central differences between the way we trust other people and the way in which we can rely on non-living objects, which is why I will base my following observations on this account.

Baier points out that there are a number of things in our lives we care about, but the flourishing of which we cannot ensure on our own. This is true if we want to keep potted plants in our flat but still go on holiday in summer. It is true if we care about 
the education of our children. It is trivially true of any personal relationship we might want to pursue.

Not denying that in ordinary language we talk about trust in a number of different ways, Baier suggests differentiating between trust and reliance. According to Baier we can rely on people as well as non-living-objects. Reliance means the expectation of a favorable outcome, without any reference to another person's goodwill. Trust, with Baier, is the narrower term. It is a form of reliance, but a specific one. When we trust, we rely on a favorable outcome to occur because we expect a certain person to act with a specific attitude towards us. Trust is the reliance on the goodwill of other persons. If we think that a certain café is going to serve us good coffee just because it is in the owner's and employee's best interest to do so to successfully make money in the future, we are merely relying on something. If we know the barista personally and believe she would never serve us bad coffee out of a specific regard for us, we are trusting her (Baier 1996).

To capture specific instances of trust more clearly, Baier has propagated that it should always be understood as a three-place relation: "A trusts B with valued thing C" (Baier 1996). A is the person trusting. B is the person trusted. C is something with a certain degree of importance to us, the flourishing of which in one sense or another we entrust to B. I can thus entrust the well-being of my flowers to my neighbor while I am on holiday or entrust the education of my child to the school I am sending her to. Insofar as I care about $\mathrm{C}$, trust always involves an element of vulnerability. B is given the opportunity to hurt me by not taking appropriate care of the object or person I entrusted to her.

This analysis might not be the best to capture the deep but diffuse feelings of trust we often encounter in close personal relationships. But it successfully captures a number of relevant dimensions of trust. One aspect Baier focuses on is that an act of trust usually transfers responsibility for something very specific to another person and that this implies the transfer of some discretionary power: B has some leeway to decide how to best care for $\mathrm{C}$. Only in very few cases of trust do we have some exact action of another person in mind.

A second aspect of trust that Baier does not consider but which can easily be integrated into her account is an ascription of competence: even if I believe your goodwill to be boundless, this might not be sufficient for me to trust you with my child. I will do so only if I also hold you to be at least moderately competent in dealing with children. Only then can I trust you to exercise your discretionary power appropriately. Bernard Barber elaborates on this aspect in his book The Logic and Limits of Trust. He points out that this aspect is especially important when it comes to trust in competent role performance: if I trust my doctor, an estimation of competence is an important part of that trust (Barber 1983).

While trust might be considered typical for close personal relationships, Baier assumes that we can also trust in strangers (Baier 1996). If I am on a train and I want to use the lavatory, I might ask a person sitting across from me to watch my things 
while I am gone. Trust here is still the reliance on the goodwill of that other person. Insofar as goodwill is a moral attitude, Baier presupposes that we stand in a moral relationship to strangers: we are part of a moral community and we often take this as sufficient reason to meet each other with a minimal sense of trust. When we talk about trust relationships, however, we usually have a different kind of relationship in mind: relationships of high trust are relationships between persons who are well acquainted and feel emotionally close to one another. They rely on each other's goodwill not in the sense of a moral attitude shared by all members of a moral community but in the sense that they trust the other to consider their well-being before and above the well-being of strangers. Friendships, romantic relationships and many family ties are conceptualized in such a way.

The relationship between caregiver and a person receiving care will usually fall somewhere in between a weak personal relationship with a minimal sense of trust and a more dense, high-trust personal relationship. We usually trust in caregivers to be at least decent human beings who do not abuse the vulnerability of those they care for. We also wish for caregivers to develop a personal regard for the people they care for and thus hope for them to show themselves to be well-meaning beyond the simple demands of general moral obligations and the specific duties of their role. This is one sense in which we expect them to be caring persons. Sometimes, caregivers are even family members with a long-standing trust relationship to the person cared for. This does not exclude the possibility, however, that some care relationships turn out not to be trust relationships at all. Some of them might be relationships of deep mistrust. I will discuss the implications of this possibility later.

On this account, we cannot stand in a trust relationship to a care robot or any other kind of technological device. First of all, because trust requires a reference to the goodwill of the trusted. While science-fiction movies tend to project spectacular scenarios in which robots come to act and feel like human beings, I assume here that we agree that our current technologies at least are not, in the relevant sense, capable of being well-meaning. I do not consider them to be moral agents ${ }^{15}$. The significant difference, I believe, is that we have no reason to hold technological devices accountable for the actions they take based on their programming.

Furthermore, we can point out that the discretionary power we can sensibly attribute to robots is limited. I do not mean to say that they cannot react flexibly to changing circumstances. The whole point of artificial intelligence is to give them the ability to be able to do so. But we should not assume that they could use their empathetic

15 I am little concerned here with the much debated question if machines could someday become moral agents. I do not deny that their performance has ethical impact or that their code can be better or worse in regard to avoiding negative impact, I simply deny that this is sufficient reason to talk about them as moral agents. For detailed discussions of this question compare (Moor 2006; Wallach and Allen 2010). 
powers to consider how much control we likely intended to give them. Their range of possible responses needs to be precisely defined during development. Lastly, we should not expect care robots to form emotional bonds. They do not have the necessary emotional capacities to care about us as an individual and to prefer us above others. In short: we cannot stand in a moral or emotional relationship to care robots.

\subsection{Reliance}

There are other accounts of trust that do not conceptualize it as a moral relationship at all. When excluding robots as recipients of trust, one might thus wonder if I have not simply chosen the wrong account of trust for the endeavor. Indeed, there is a relevant sense in which we can rely on robots that is often referred to by the word "trust" in everyday language. I will further elaborate on this account of trust now, however, I wish to state that I am not concerned with a fight about words. One can talk about trust in a wide sense and in a narrow sense. Or one can call one relation trust and the other reliance, as Baier does. The importance is not which terms we use but in marking the differences between the two concepts.

One prominent author who conceptualizes trust in the sense that Baier talks about reliance is the German sociologist Niklas Luhmann. Luhmann provides us with an in-depth analysis of why we need trust in our lives: trust enables us to reduce the perceived complexity of the world around us and thus provides us with more options of practical action by allowing us to neglect considering some unfavorable outcomes. Trust, in the wide sense of reliance, allows us to ignore that things could turn out bad. We therefore trust in the bridge not to break under our feet, we trust the public transport system to bring us to work (if not necessarily quite on time), we trust our babysitter not to abduct our child. If we took into account that any of these might happen and tried to guard against them, our lives would immediately become much more complicated (Luhmann 2009).

In this account of trust, the goodwill of a person plays no necessary role. It is not of any great importance why certain things are not going to happen, it is simply important that we rely on them not to happen. Personal attitudes are not presupposed in this wider conception of trust. In this sense then, we can put our trust in technological devices. To mark the difference between the two concepts, I will from here follow Baier and not use the term trust in a narrow sense but instead talk about reliance.

Let us assume I prepare a PowerPoint presentation for a talk and I decide not to print out a handout. I would consider such a handout to be necessary for me presenting well if I did not have my slides. In this case I am relying on my computer. When we enter the phone number of a friend into a smartphone without also writing it down on a piece of paper we are relying on that phone's memory. Here again it is imprecise to simply say that I rely on my smartphone without specifying in regard to which function I am relying on it. I do not rely on my smartphone to remind me to actually call 
that friend. It would be irrational to do so without first setting up a reminder. Nor do I rely on it to tell me when he is sad and might particularly appreciate a call.

So I propose to conceptualize reliance analogously to trust as a three-way relation: A relies on $\mathrm{B}$ in regard to $\mathrm{C}$. A, again, is a person. $\mathrm{B}$ can now be a person or a tool or a technological device. $\mathrm{C}$ can be a specific act or a function. Relying on a technological device then also presupposes ascribing to it the relevant functionality (and me having made use of that functionality), as trusting a person necessitates ascribing to them the relevant competencies.

\subsection{Trust, reliance and valuable life options}

The inherent value of trust relationships is often stressed, while our dependence on technological devices is often criticized. But both, I believe, can contribute to a good life. Trust relationships, it is often argued, are themselves a valuable aspect of a good life for most human beings. The capabilities approach, for example, assumes that our conception of a good life involves the ability to form close emotional bonds and to live with and for others (Nussbaum 2013). And it seems very reasonable to assume that we do not want those bonds to be bonds of mistrust. But even beyond close personal ties many of us prefer to live in an atmosphere of trust (Hartmann 2011; Fukuyama 1996; Williams 2004). Trust relationships are additionally of instrumental value to us, as Baier points out, because we can only care about a very limited number of things in our life if we do not want to trust in others. The option to have children and to pursue a career, for example, is only available to us if we can entrust the care for our children to someone else while we are at work.

Technological devices are valuable to us only insofar as we derive something of value from the function they fulfill and the options they offer. Riding an elevator is not considered to be of intrinsic value. Without elevators, however, houses with more than six stories seem less like a plausible option for living. Without my computer and the option of emails, I could not stay in regular contact with as many colleagues as I actually do. I can also rely on my TV and Netflix to provide me with regular evening entertainment. While the value of such options is always an instrumental value, they can be valuable and important for a good life nonetheless.

\subsection{Broken trust and disappointed reliance}

Before I go on to talk about some ethical implications of the differences between trust and reliance I want to carry this conceptual analysis one step further by looking at harm and disappointment as it can occur in both cases. And I am here especially interested in the options open to us when we are faced with such a disappointment. 
If our trust is broken, something we value has not been taken good care of and we perceive ourselves as harmed. We become aware of the inherent vulnerability in every act of trusting. We often react to broken trust according to our relationship with reactive moral attitudes. ${ }^{16}$ We are not only disappointed and hurt by the outcome, we are also disappointed in someone. This disappointment can manifest as a more general disappointment with the community we live in if the person to disappoint our trust is a stranger. It will be directed specifically at the person we trusted if we had perceived this person as deliberately presenting herself as trustworthy in the past. Depending on the circumstances, we might easily forgive a minor breach of trust, or we might decide on some kind of punitive action as a response to it. The reaction I am most interested in here, however, is our option to blame.

I understand blame, following Angela M. Smith, as a moral protest of an agent's treatment of oneself or others:

To morally blame another, in my view, is to register in some significant way one's moral protest of that agent's treatment of oneself or others. Such protest need not be outwardly expressed in any way (...). But what unites all of the behavioral and attitudinal responses we are inclined to categorize as instances of blame (...) is that they share this element of moral protest. (Smith 2013)

The act of blaming encompasses the judgment of some person being blameworthy as well as a modification of "attitudes, intentions and expectations of the blameworthy agent" that can be understood as a protest (Smith 2013). This account of blame, like others, presupposes accountability. McKenna formulates clearly what is meant by this:

Moral responsibility in this sense [author's note: in the sense of accountability] involves the possibility of holding an agent to account for her conduct, and thereby seeing her as properly responsive to our demands and sanctions. Such an agent is one who can be expected to acknowledge and comply with others' moral expectations. (McKenna 2013)

Blame then as well as trust needs to be understood in a moral context. It presupposes that we share a set of moral norms and that we perceive ourselves as members of a moral community.

Not always, but often, when we lay blame on a person we expect a reaction. We might confront the person with our complaint and receive an apology. We might voice

\footnotetext{
16 Some of the accounts of blame I am referring to in this article explicitly distance themselves from a reactive-attitude account of blame. My assumption here that disappointed trust typically leads to reactive moral attitudes and to blaming does not contradict those positions. The central question of the debate is not about blame usually going along with reactive moral attitudes in a wider sense - hardly anyone would deny that - but strictly about the question if being a reactive moral attitude is a constitutive feature of every instance of blame. This question is of some philosophical relevance but of little practical relevance here.
} 
our blame to others to get acknowledged for its legitimacy. We want our moral protest to be heard, especially if it is directed towards a person with whom we stand in a continuing relationship. Protest challenges an unacceptable moral presumption and ultimately aims at a change of behavior - we demand to be treated better (Smith 2013).

While we can talk in everyday language about blaming artifacts, we do not mean it in the sense just described. If I blamed my computer for not being able to finish this article in time, I would only be claiming a causal relation - my computer was malfunctioning, thus I could not complete my draft. Blame as a moral protest is not applicable here as my computer is not a moral agent and it is thus impossible for me to perceive myself as standing in a moral relationship to it. I do not hold it accountable. I do not expect it to change its behavior because I confronted it with my protest. I will simply be disappointed that it is malfunctioning.

In cases of disappointed reliance, we are also hurt insofar as something negative has happened that we were not expecting. Reliance, like trust, implies a certain vulnerability. Moral protest, however, is not a rational option. We might adopt reactive attitudes for a short moment, when we feel like smashing in the screen of our computer, but we do not seriously believe that our expression of such attitudes in the form of protest might have any effect on the situation. The resulting disappointment can be self-directed: it is my own fault that I bought this model and was relying on it to continue functioning so that I could finish my draft in time. Or we can search for another responsible party to blame: I can blame the people who produced and sold me a malfunctioning device. I can hold them accountable, even though they are distant and anonymous agents. In many cases, however, we will not blame them. Either because we do not perceive them as having done anything wrong, or because we never expected them to act with any goodwill towards us in the first place.

\subsection{Intermediary conclusion: On the possibility of replacement}

As I have shown so far, trust and reliance can be described as two distinct phenomena. Both structure our expectations of future developments, but in their further implications, they differ. Trust is an important component of moral and personal relationships. It refers to the goodwill of a person. Trustworthiness itself is then the manifestation of a well-meaning attitude and can be the expression of a special regard. Trust thus can be regarded as a constitutive feature of inherently valuable human relationships, in which we experience things like love and appreciation for our personality.

In this sense, technological devices in general and care robots more specifically, cannot replace a caregiver to whom we can stand in a trusting relationship. Such devices and my reliance on them can only be of instrumental value in my life. If we consider replacing caregivers with assistive devices, we need to be absolutely clear that this can only ever be a partial replacement in regard to some well specified func- 
tion. There is no potential of this being a trust relationship. If a person's mobility is limited another person as well as a care-robot could help her regain better mobility. If a person is in danger of dehydration because she does not remember to drink and also lacks the ability to walk to the kitchen to get water, a person or an assistive technology device could remind her that it is necessary to drink and bring water. But it is only in regard to those very specific tasks that replacement is possible.

\subsection{Trust, vulnerability and dependence}

Trust is often praised as a valuable human capacity, but it always includes the risk of being hurt. Trust presupposes vulnerability (Baier 1996; Luhmann 2009; Hartmann 2011). Baier clearly rejects the stoic ideal of only attaching oneself "to what can thrive or be safe from harm, however others act” (Baier 1996). Following this ideal we would have no need for trust. But it also leaves us very little that we may actually care about. This is not how most of us wish to live their lives.

The issue of vulnerability in trust becomes even more pronounced when we look at unequal trust relationships. In the discussion on trust, Baier has voiced a central complaint against earlier, mainly contractualist theories of trust: in the context of contractualism, trust was given an important role, but it was always conceptualized as a trust between partners of equal standing with equal opportunity to sanction deviant behavior. ${ }^{17}$ Many trust relationships, however, are not between equals. The vulnerability inherent in trust becomes a lot more pronounced in these relationships. Infant-parent relations can be seen as the prototype of unequal trust. Baier points out that for the longest time married women predominantly stood in unequal relationships with their husbands who held positions of superior power (Baier 1996). What should be a trust relationship can become a relationship of repeatedly broken trust or even a relationship of mistrust. We might not believe in the goodwill of a person at all anymore, but still be in a position of dependence where we need to rely on another for the flourishing of the things we care about, among those our own well-being.

Caregiving relationships are often unequal relationships in this sense. People in need of care are in a position of greater than usual dependence. They will have varying degrees of influence on who is caring for them under what circumstances. The

17 Baier refers here to Humes's example of two farmers who trust in each other on the basis of a promise: The farmer, who has to help his neighbor first, but has to wait for this help to be reciprocated at a later date. The farmer's vulnerability, however, is reduced by his equal standing: by trusting his neighbor, he first accepts a certain degree of vulnerability. If the promise is not kept he has every option to spread his discontent and harm his neighbor's reputation. Both need to consider options to cooperate in the future among themselves and with others. As far as their relationship is to a certain degree public, there is a second level of vulnerability on both sides: both can threaten the other's standing in society and chances of future cooperation. Hume (2009); Baier (1996). 
less influence they have, the more they are vulnerable: they depend on others for their well-being and flourishing somewhat more than most other (healthy and adult) persons. Depending on circumstances, they might also have less power in regard to shaping their relationship to the person giving care and it might be less likely that the moral protests they voice will be heard.

The high degree of dependence that is a necessary circumstance of relationships between young children and their parents seems more difficult for us to accept in old age, no matter if it is the parent now being dependent on the adult child, or someone depending on another family member or a care professional. While we should not forget that relationships to a human caregiver can be rewarding social relationships and can fulfill the need for social relationships we all have, we should also not forget that not all human relationships are perceived as rewarding. Care relationships can turn out to be relationships of broken trust or mistrust. We can be repeatedly hurt in those relationships; we are especially vulnerable when circumstances do not allow us to decide for ourselves if we want to end them. It seems thus reasonable to pursue the thought that access to assistive technology can reduce our vulnerability and allow us more independence.

\subsection{Vulnerability and types of risks}

It seems to be an undeniable truth that human beings are vulnerable (Birnbacher 2012). Nevertheless, references to vulnerability in the context of medical ethics and bioethics have been under critique for over-simplifying matters and stigmatizing groups. Children, people with disabilities as well as pregnant women have repeatedly been classified as vulnerable groups without due attention to specific individual circumstances (Wild 2014). We should thus be careful to classify older adults or people living in retirement homes as vulnerable per se.

This difficulty in identifying the vulnerable, however, does not alter our moral intuition that those especially vulnerable have some right to be specially protected (Hurst 2008). It is necessary to assume, though, that there is not one type of vulnerability and that the label cannot be fixed as an attribute to a specific group of people. In thinking about vulnerability it is important to give a clear account of what is meant by the term in a specific context.

Derek Sellman suggests an account of human vulnerability to better grasp its meaning in the context of nursing. He suggests conceptualizing vulnerability in terms of risks: being vulnerable means being open to a certain type of risk. ${ }^{18}$ Sellman offers a distinction of three types of "risks of harm" (Sellman 2005):

18 I agree with Hurst (2008) that this cannot be considered an exhaustive definition of the term. It will nevertheless be sufficient for the purpose of this article. 
a. First of all, as an individual we are vulnerable to risks we could potentially take precautions against. We are, for example, at risk from traffic accidents but we can choose to be careful participants of street traffic to minimize this risk. A risk can be measured in degrees of probability and minimizing a risk means reducing its probability, even if it cannot be completely eliminated.

b. In the second category, we have risks that we cannot protect against by ourselves and where we need other people to help us reduce the risk. This is the category of risk to which patients and clients of care are more vulnerable than other people: Their ability to protect themselves is limited in at least some respect. They are thus in need of more assistance to ensure their well-being and potential of flourishing. As human beings we are, for example, vulnerable to the risk of dehydration. Minimizing this risk by drinking regularly does not pose a challenge for most of us. It only becomes visible as a risk of the second category when we lose the ability to determine when we are in need of fluids or the ability to move around our flat to get a glass of water. Many risks are little perceived as long as they fall into the first category and only become apparent through a shift to the second category: they do not appear to us as risks until we lose some ability we had so far been taking for granted.

c. The third category describes how we are vulnerable to events we cannot influence at all-like earthquakes. When we state that all human beings are vulnerable, we often think about this category more than the first category. We think of our vulnerability to events that are from a personal perspective described as strokes of fate: they appear to be unpredictable and there is nothing much we can do to protect against them.

If trust necessarily involves a component of vulnerability, this particular vulnerability falls into the second category: by every act of trust, we allow our well-being to be more dependent on the actions of some other person. In the context of trust, some authors talk about accepted vulnerability (e. g. Hartmann 2011). This shows that the good at stake could potentially be cared for by ourselves (even if the cost might be high), strictly limiting all risk to category (a). While this is possible in a single instance of trust, we should not forget what Baier as well as Luhmann point out: our options to care for things we perceive as valuable would be severely limited if we ever tried not to trust at all. But we can and do decide not to trust in specific instances, e. g. by deciding to do something ourselves, by checking on the people we distrust, or by choosing a different agent in whom to place our trust.

The case seems to be different in the context of care: being open to some specific risk we cannot guard ourselves against constitutes being in need of care. When we have lost the ability to protect ourselves against a certain risk, we cannot simply affect a shift back to category (a). Depending on the circumstances we might recover our lost ability, of course. But recovery cannot be understood as a simple decision and might in spite of our best efforts stay out of reach. Looking at Sellman's categories of risk, 
the exchange of human caregivers with assistive technology devices then implies an option to reduce vulnerability. When we have the option to rely on a technological device, we regain something equivalent to the option not to trust. As assistive devices are not other people their use seems to imply a shift away from category (b): the need to rely on others. They promise greater independence; they provide the option to choose between trusting others to protect us or relying on ourselves and the use of assistive technology.

Is it plausible, however, to interpret the replacing of a caregiver by an assistive device as a shift from category (b) to category (a)? It is not like the specific risk that constitutes our need for care itself has vanished. It might seem debatable if the necessity to rely on an assistive device can really be understood as an increase of our own abilities, thus reducing dependence.

Reliance implies its own kind of dependence and thus, just like trust, can imply vulnerability. Should we not then extend Sellman's categories by a fourth, somewhat like the following:

d. We are vulnerable against risks that we can guard against by using technological devices.

We would soon have to broaden the category, though, as technological devices do not appear sufficiently different from other tools and objects we rely on. Tools as well can break or malfunction. But if we add every type of tool used by humans into this category, Sellman's suggested category (a) would be almost empty. There are few risks we can guard against by simply being careful. We use a high number of different kinds of tools in almost all areas of our life. Thus, it seems to make more sense to understand the use of tools or technological devices as actions that bridge categories (a) and (b) - we are dependent on others to a degree to ensure the functioning of those tools. But as long as they do function and we can use them we gain a degree of independence and the ability to guard ourselves from risks. Insofar as the use of technological devices only implies a partial shift and necessarily includes an element of dependence regarding the functionality of our device, reliability becomes a key factor in evaluating the usefulness of assistive technologies. We are vulnerable whenever our assistive device does not fulfill its function and in regard to this vulnerability we are dependent on the people responsible for the functioning and maintenance of our assistive device.

\subsection{Potential and limitations of assistive technology devices}

In this paper, I set out to consider some ethical aspects of the implementation of assistive technologies in contexts where these are designed to directly interact with humans without standing under the direct control of another person. The paper has focused on discussing some implications of the fact that trust in interpersonal rela- 
tionships can be understood as a moral concept and thus needs to be distinguished from the possibility of relying on technological devices. While both trust and reliance refer to the expectation of a favorable outcome I have suggested to follow Baier in differentiating between the two conceptions.

Trust as reliance on the goodwill of others constitutes a moral relationship and plays a great role in the flourishing of things we care about. A trust relationship always needs to be described in reference to some valuable thing we trust to another and presupposes an ascription of competence as well as a conveyance of a certain limited discretionary power to the person trusted. While we can trust strangers in this sense, trust is typically seen in the context of high trust relationships that presuppose intimacy as well as an emotional bond. Professional relationships between caregivers and receivers of care are not usually conceptualized as intimate relationships but are nevertheless generally perceived as relationships of trust. Trust relationships can be perceived as inherently valuable and are often seen as a necessary component of a good life.

Assistive technology devices cannot be considered adequate recipients of trust. Care robots thus cannot be considered to replace caregivers in their function as a person trusted. In regard to these devices we are limited to the option of relying on them. Reliance, like trust, describes the expectation of a favorable outcome and needs to be specified in regard to specific functions of a device. It does not, however, imply the specific attitude only a person can have toward us and neither does it imply the transfer of discretionary power - instead we would often prefer to know exactly how our assistive system is going to react in a specific set of circumstances. It is commonly assumed that reliance does not realize any intrinsic, but only instrumental value.

Trust relationships, as other human relationship, bear the potential of great hurt and disappointment. Not only will the flourishing of the good we care about not be realized when our trust is disappointed, but a breach of trust can also be perceived as denying our moral status. Blame is a common reaction to disappointed trust and a form of protest against the way we have been treated. Blame is a way for us to demand to be acknowledged. Our chances to be acknowledged, however, depend on the particular circumstances of the relationship. The vulnerability that necessarily comes with trust is increased in unequal trust relationships where the person trusting depends to a higher degree on the person trusted. Due to the need of care of one party, care relationships will often constitute unequal relationships in this sense.

Because of the vulnerability and risk to harm not all trust relationships can be perceived as valuable and in many circumstances it is reasonable for us not to trust in others. Especially in unequal trust relationships the option to leave needs to be perceived as valuable. Assistive technology devices can under some circumstances offer us the choice not to trust where without their availability we have no choice but to be dependent on another person to guard us against specific risks and where we possibly have little choice in whom to trust. Regaining the choice not to trust another person 
or to end a relationship of mistrust can prima facie be seen as valuable as it gives us the option for more autonomy.

As reliance on an assistive device can never replace all components of a functioning trust relationship, they can under this perspective not appear as the preferable option in general, but only where the choice between a human caregiver and an assistive device is given. Relying on assistive technology devices constitutes its own form of dependence and poses its own risks. Relying on them can only be a rational option if they indeed prove their reliability in guarding us against the specific risks that constitute our need for care. As long as they do not perform without fault $100 \%$ of the time they comprise a dependence on the company and people providing supervision, maintenance and repair. If this support is not reliable, again, people are exposed to a risk they cannot guard against.

However, we should also not forget that assistive technology devices might become much better at fulfilling some instrumental functions than human caregivers could ever be. They could in this case still not completely compensate a lost trust relationship, but prove to have other advantages. The best option in many cases would thus appear to be a working trust relationship to a human caregiver as well as the availability of some assistive technology. Nor should we forget that assistive technology devices can harm us or violate our rights in many other ways, as further contributions to this volume show; through deception, through violations of privacy by constant data collection, through reduced access to human caregivers due to budget cuts in lieu of cheaper alternatives - to name but a few issues in the debate.

\section{References}

Baier, Annette C. 1996. Moral prejudices. Essays on ethics, 3 rd edn. Cambridge, Mass.: Harvard Univ. Press.

Barber, Bernard. 1983. The Logic and Limits of Trust. New Brunswick: Rutgers University Press.

Becker, Stefanie. 2017. Demografische Herausforderungen. In Pflege im Wandel gestalten - Eine Führungsaufgabe, ed. Peter Bechtel, Ingrid Smerdka-Arhelger and Kathrin Lipp, 17-26. Berlin, Heidelberg: Springer.

Beer, Jenay M., Arthur D. Fisk, and Wendy A. Rogers. 2014. Toward a framework for levels of robot autonomy in human-robot interaction. Journal of human-robot interaction 3 (2): 74-99. doi: 10.5898/JHRI.3.2.Beer.

Bemelmans, Roger, Gert Jan Gelderblom, Pieter Jonker, and Luc de Witte. 2015. Effectiveness of Robot Paro in Intramural Psychogeriatric Care: A Multicenter Quasi-Experimental Study. Journal of the American Medical Directors Association 16 (11): 946-950. doi: 10.1016/j. jamda.2015.05.007.

Birnbacher, Dieter. 2012. Vulnerabilität und Patientenautonomie - Anmerkungen aus medizinethischer Sicht. Medizinrecht 30 (9): 560-565. doi: 10.1007/s00350-012-3223-1.

Bryson, Joanna J. 2010. Robots should be slaves. Close Engagements with Artificial Companions: Key social, psychological, ethical and design issues: 63-74.

Bundesministerium für Bildung und Forschung. 2018. Pflege durch Forschung erleichtern. https:// www.bmbf.de/de/pflege-erleichtern-5479.html. Accessed 13 April 2019. 
Fukuyama, Francis. 1996. Trust. The social virtues and the creation of prosperity, 1st edn. New York, NY: Free Press.

Gräb-Schmidt, Elisabeth, and Christian P. Stritzelberger. 2018. Ethische Herausforderungen durch autonome Systeme und Robotik im Bereich der Pflege. Zeitschrift für medizinische Ethik (64): 357-371.

Graf, Birgit, and Barbara Klein. 2018. Robotik in Pflege und Krankenhaus: Einsatzfelder, Produktue und aktuelle Forschungsarbeiten. Zeitschrift für medizinische Ethik (64): 327-343.

Hartmann, Martin. 2011. Die Praxis des Vertrauens. Frankfurt/Main: Suhrkamp.

Hume, David. 2009. A Treatise on Human Nature. Being an Attempt to Introduce the Experimental Method of Reasoning Into Moral Subjects. [S. I.]: The Floating Press.

Hurst, Samia A. 2008. Vulnerability in research and health care; describing the elephant in the room? Bioethics 22 (4): 191-202. doi: 10.1111/j.1467-8519.2008.00631.x.

Luhmann, Niklas. 2009. Vertrauen. Ein Mechanismus der Reduktion sozialer Komplexität, 4th edn. UTB für Wissenschaft Soziologie fachübergreifend, vol. 2185. Stuttgart: Lucius \& Lucius.

McKenna, Michael. 2013. Directed Blame and Conversation. In Blame: Its nature and norms, ed. D. Justin Coates and Neal A. Tognazzini, 119-140. Oxford: Oxford University Press.

Moor, James H. 2006. The nature, importance, and difficulty of machine ethics. IEEE intelligent systems 21 (4): 18-21.

Nussbaum, Martha Craven. 2013. Creating capabilities. The human development approach. Cambridge, Massachusetts, London, England: The Belknap Press of Harvard University Press.

Pfeiffer, Stephanie. 2018. Commitment in der stationären Krankenpflege. Organisationsbindung als unternehmerische Ressource des Personalmanagements. Best of Pflege. Wiesbaden: Springer Fachmedien.

Sahmel, Karl-Heinz. 2018. Pflegenotstand - ist das Ende der Menschlichkeit erreicht? Pflegezeitschrift 71 (6): 18-22. doi: 10.1007/s41906-018-0535-4.

Sellman, Derek. 2005. Towards an understanding of nursing as a response to human vulnerability. Nursing Philosophy (6): 2-10. doi: 10.1111/j.1466-769X.2004.00202.x.

Smith, Angela M. 2013. Moral Blame and Moral Protest. In Blame: Its nature and norms, ed. D. Justin Coates and Neal A. Tognazzini, 27-48. Oxford: Oxford University Press.

Wallach, Wendell, and Colin Allen. 2010. Moral machines. Teaching robots right from wrong. Oxford, New York, Hong Kong, Madrid, Toronto: Oxford University Press.

Wild, Verina. 2014. Vulnerabilität. In Handbuch Ethik und Recht der Forschung am Menschen, ed. Christian Lenk, Gunnar Duttge and Heiner Fangerau, 297-298. Berlin, Heidelberg: Springer.

Williams, Bernard. 2004. Truth \& truthfulness. An essay in genealogy, 4th edn. Princeton paperbacks. Princeton: Princeton Univ. Press. 
